\title{
Faktor-Faktor yang Berpengaruh Terhadap Perilaku Seksual pada Remaja di SMA Karya Handayani Langga Payung Tahun 2020
}

\author{
Elpiana Sari \\ Program Studi Keperawatan, Institut Teknologi dan Kesehatan Sumatera Utara.
}

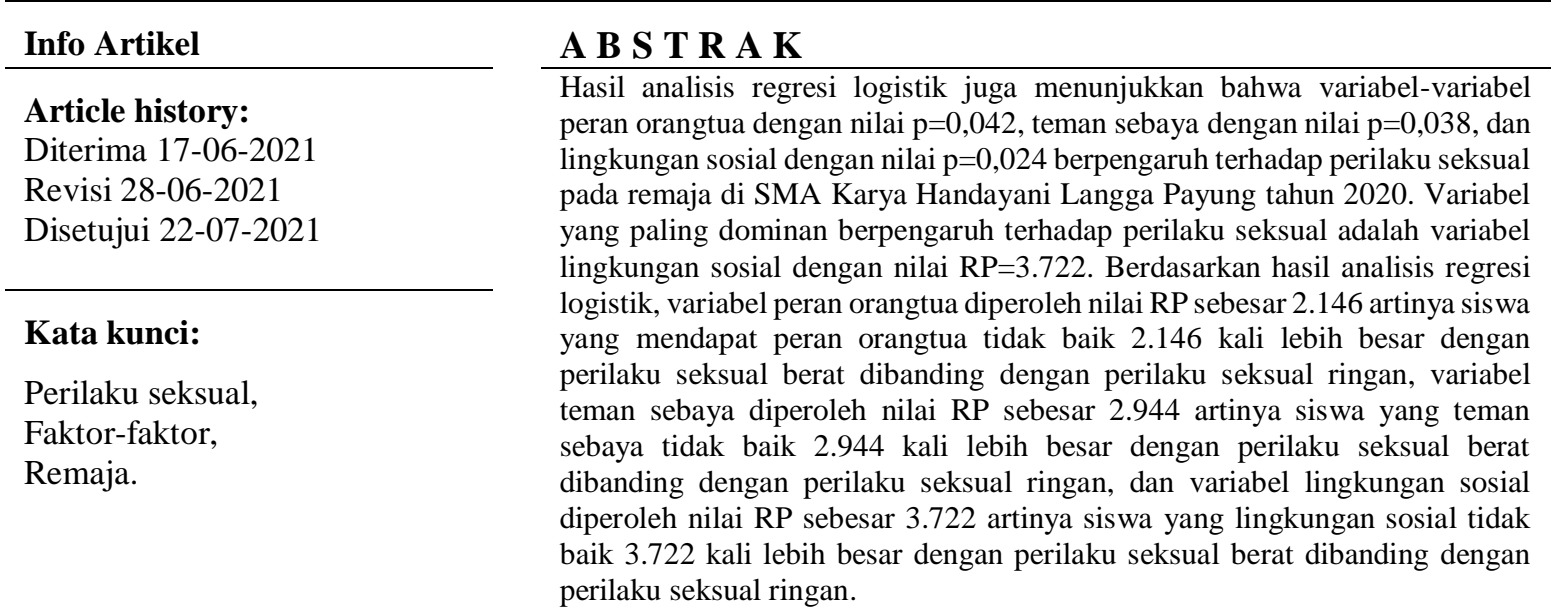

\section{Koresponden Penulis:}

Elpiana Sari,

Program Studi Keperawatan, Institut Teknologi dan Kesehatan Sumatera Utara,

Jl. Trans Sumatera Bukittinggi - Padang Sidempuan, Sihitang, Padangsidimpuan Tenggara, Kota Padang Sidempuan, Sumatera Utara 22733.

Email: elpianasari10@gmail.com

\section{PENDAHULUAN}

Remaja merupakan harapan bangsa, sehingga tak berlebihan jika dikatakan bahwa masa depan bangsa yang akan ditentukan pada keadaan remaja saat ini. Remaja yang sehat dan berkualitas menjadi perhatian serius bagi orangtua, praktisi pendidikan, ataupun remaja itu sendiri. Remaja yang sehat adalah remaja yang produktif dan kreatif sesuai dengan tahap perkembangannya. Remaja Indonesia saat ini sedang mengalami perubahan sosial yang cepat dari masyarakat tradisional menuju masyarakat modern, yang juga mengubah norma-norma, nilai-nilai dan gaya hidup mereka. Remaja yang dahulu terjaga secara kuat oleh sistem keluarga, adat budaya serta nilai-nilai tradisional yang ada, telah mengalami pengikisan yang disebabkan oleh urbanisasi yang cepat dan industrialisasi yang cepat (Poltekkes Depkes Jakarta I, 2010).

Menurut World Health Organization (WHO) tahun 2009 sekitar 16 juta perempuan berusia 15-19 tahun melakukan hubungan seksual pranikah. Sekitar 14\% dari kejadian aborsi yang tidak aman. Sekitar 2,5 juta remaja berusia dilaporkan melakukan aborsi tiap tahun berumur 15-19 tahun.

Di Indonesia frekuensi terbesar remaja yang pernah melakukan hubungan seks pranikah berada pada kelompok umur 20-24 tahun yaitu sebesar 60,1\%, remaja yang mengalami kehamilan yang tidak diinginkan sebanyak 58,5\% berada pada umur 15-19 tahun dan rata-rata 19 tahun remaja telah melakukan aborsi. Menurut Survei Demografi Kesehatan Indonesia (SDKI) tahun 2012 menunjukkan kelompok umur 20-24 tahun pada wanita yaitu sebesar 1,8\% telah melakukan hubungan seksual sebelum menikah dan pada pria sebesar 14,6\%. Kelompok 15-19 wanita telah melakukan hubungan seksual sebelum menikah sebesar $0,7 \%$ dan pada pria sebesar 4,5\%. 
Dari survey pendahuluan yang dilakukan pada 10 siswa-siswi SMA Karya Handayani Langga Payung, mereka adalah yang tinggal bersama orangtua. 8 diantaranya sudah pacaran, 2 orang mengatakan hubungannya dengan kata lain teman dekat. Dari 10 orang siswa-siswi yang sudah berpacaran 3 orang mengatakan sudah mulai berpegangan tangan, dari 10 siswa-siswai 5 orang juga mengatakan berpacaran sudah dengan meraba-raba bagian sensitif, dilakukan juga khusus pada siswa laki-laki yang sudah merokok. Hasil wawancara dengan Kepala Sekolah SMA Karya Handayani Langga Payung dari tahun 2015-2019 terdapat 5 orang siswi hamil di luar nikah dan pada tahun 2017 di lingkungan yang sama terdapat 2 orang siswa (1 pasang siswa-siswi) SMA melakukan perilaku seksual meskipun tidak dinyatakan hamil, hal ini dengan maraknya media internet, kurangnya iman, pergaulan bebas, kurangnya pengawasan dari orangtua yang membuat lingkungan tidak terkontrol oleh orangtua sendiri dengan alasan anak keluar mencari tugas, tetapi kenyataannya membuka internet untuk melihat perilaku seksual. Bahkan guru-guru pun merasa kewalahan juga untuk mengarahkan para siswa-siswi untuk menjadi lebih baik kedepannya "ujar Kepala Sekolah".

Berdasarkan latar belakang di atas perumusan masalah dalam penelitian ini faktor-faktor apa saja yang berpengaruh terhadap perilaku seksual pada remaja di SMA Karya Handayani Langga Payung tahun 2020.

\section{METODE PENELITIAN}

\section{Jenis Penelitian}

Jenis Penelitian ini menggunakan rancangan Cross Sectional. Rancangan penelitian Cross sectional adalah merupakan penelitian dimana peneliti mencari hubungan antara variabel bebas dengan variabel terikat yang terjadi pada obyek penelitian diukur atau dikumpulkan dalam waktu yang bersamaan.

\section{Lokasi dan Waktu Penelitian}

Penelitian ini dilakukan di SMA Karya Handayani Langga Payung Tahun 2020. Waktu penelitian dilaksanakan mulai dari bulan Februari sampai dengan Agustus 2020.

\section{Populasi dan Sampel}

Populasi dalam penelitian ini adalah seluruh seluruh siswa-siswi kelas I dan II yang ada di SMA Karya Handayani Langga Payung. Besar sampel sebanyak 65 orang. Teknik sampel yang digunakan adalah total sampling yaitu seluruh siswa-siswi dijadikan sampel yaitu sebanyak 65 orang. Kerangka konsep penelitian terdiri dari variabel bebas yaitu umur, pengetahuan, sikap, media informasi, peran orangtua,teman sebaya, lingkungan sosial. Sedangkan variabel terikat adalah prilaku seksual remaja.

Data yang dikumpulkan meliputi data primer dan data sekunder. Data primer diperoleh melalui kuesioner dan data sekunder data yang diperoleh dari dokumen SMA Karya Handayani Langga Payung.

Metode Analisis Data

1. Analisa Univariat

Analisis univariat dilakukan untuk memperoleh gambaran tentang distribusi frekwensi masing-masing variabel independen meliputi umur, pengetahuan, sikap, media informasi, peran orangtua,teman sebaya, lingkungan sosial dan variabel dependen yaitu prilaku seksual remaja. Analisis univariat disajikan dalam bentuk tabel.

2. Analisa Bivariat

Analisis bivariat digunakan untuk melihat hubungan antara variabel independen umur, pengetahuan, sikap, media informasi, peran orangtua,teman sebaya, lingkungan sosial dengan variabel dependen (prilaku seksual remaja) dengan menggunakan uji chi-square pada tingkat kepercayaan $95 \%$.

3. Analisa Multivariat

Analisis multivariat adalah untuk melihat pengaruh beberapa variabel bebas secara bersamasama terhadap variabel prilaku seksual remaja sehingga diketahui variabel bebas yang paling dominan pengaruhnya terhadap prilaku seksual remaja dengan menggunakan regresi logistik berganda (logistic binary regression). 


\section{HASIL DAN PEMBAHASAN}

\section{a. Pengaruh Faktor Umur dengan Perilaku Seksual Pada Remaja di SMA Karya Handayani Langga Payung Tahun 2020}

Berdasarkan distribusi umur remaja di SMA Karya Handayani Langga Payung Tahun 2017 sebagian besar dengan umur 17-19 tahun yaitu 35 orang $(53,8 \%)$ dan sebanyak 30 orang $(46,2 \%)$ dengan umur 14-16 tahun. Hasil uji statistik dengan uji Chi Square menunjukkan tidak ada hubungan yang signifikan antara umur dengan perilaku seksual $(\mathrm{p}=0,758)$.

Berdasarkan penjelasan di atas menyatakan bahwa faktor umur bukan berdiri sendiri memengaruhi perilaku seksual pada remaja. Ada faktor-faktor lain yang menentukan seperti hubungan orangtua-remaja, self esteem, tekanan negatif teman sebaya, dan eksposur media pornografi. Usia responden dalam penelitian ini berada dalam kelompok umur 14-19 tahun dengan usia pertama kali berhubungan seks. Remaja pada masa ini memiliki keberanian untuk melakukan kontak fisik dengan lawan jenis. Gaya berpacaran remaja pertengahan sudah mulai berpegangan tangan, berpelukan hingga sampai aktivitas seksual berisiko. Terjerumus tidaknya remaja pada perilaku seksual berisiko yang dipengaruhi oleh kontrol diri remaja dalam menerapkan nilai, norma dan agama yang diyakininya (Sarwono, 2012).

Penelitian ini senada dengan hasil penelitian Mahmudah (2016) tentang faktor-faktor yang berhubungan dengan perilaku seksual remaja di Kota Padang didapatkan tidak ada hubungan bermakna antara usia dengan perilaku seksual remaja di Kota Padang ( $p>0,05)$.

Tabel 1. Tabulasi Silang Hubungan Faktor Umur dengan Perilaku Seks Pada Remaja di SMA Karya Handayani Langga Payung Tahun 2020

\begin{tabular}{lccccccc}
\hline \multirow{2}{*}{ Umur } & \multicolumn{4}{c}{ Perilaku Seksual } & \multirow{2}{*}{ Jumlah } & \multirow{2}{*}{$\boldsymbol{p}$ value } \\
\cline { 2 - 6 } & \multicolumn{3}{c}{ Berat } & \multicolumn{2}{c}{ Ringan } & & \\
\cline { 2 - 6 } & $\mathbf{N}$ & $\mathbf{\%}$ & $\mathbf{n}$ & $\mathbf{\%}$ & $\mathbf{N}$ & $\mathbf{\%}$ & \\
\hline 14-16 tahun & 14 & 46,7 & 16 & 53,3 & 30 & 100,0 & \multirow{2}{*}{$\mathbf{0 , 7 5 8}$} \\
17-19 tahun & 15 & 42,9 & 20 & 57,1 & 35 & 100,0 & \\
\hline Total & $\mathbf{2 9}$ & & $\mathbf{3 6}$ & & $\mathbf{6 5}$ &
\end{tabular}

\section{b. Pengaruh Faktor Pengetahuan dengan Perilaku Seksual Pada Remaja di SMA Karya Handayaniani Langga Payung Tahun 2020}

Berdasarkan distribusi pengetahuan remaja di SMA Karya Handayani Langga Payung Tahun 2020 sebagian besar dengan pengetahuan baik yaitu 42 orang $(64,6 \%)$ dan sebanyak 23 orang $(35,4 \%)$ dengan pengetahuan tidak baik. Hasil uji statistik dengan uji Chi Square menunjukkan ada hubungan yang signifikan antara pengetahuan dengan perilaku seksual $(\mathrm{p}=0,013)$. Hasil penelitian ini sejalan dengan teori Green yang mengemukakan bahwa salah satu faktor predisposisi terjadinya suatu perilaku adalah pengetahuan (Notoatmodjo. 2010).

Penelitian yang dilakukan oleh Pratiwi dan Hari (2010) yang mendapatkan adanya hubungan yang signifikan antara tingkat pengetahuan tentang kesehatan reproduksi dengan perilaku seksual. Dalam penelitian yang dilakukan oleh Pratiwi dan Hari itu didapatkan bahwa perilaku seksual berisiko lebih tinggi pada remaja dengan tingkat pengetahuan rendah yaitu $(15,1 \%)$ dibandingkan dengan tingkat pengetahuan menengah $(7,2 \%)$ dan tingkat pengetahuan tinggi $(5,2 \%)$ (Pratiwi, 2010).

Hasil dilapangan ditemukan sebagian besar dengan pengetahuan baik yaitu 42 orang $(64,6 \%)$ disebabkan sebagian dari remaja mendapat informasi dari media elektronik dan sebanyak 23 orang $(35,4 \%)$ dengan pengetahuan tidak baik, hal ini disebabkan belum adanya penyuluhan tentang perilaku seks bebas di SMA Karya Handayani Langga Payung.

Tabel 2. Tabulasi Silang Hubungan Faktor Pengetahuan dengan Perilaku Seksual Pada Remaja di SMA Karya Handayani Langga Payung Tahun 2020

\begin{tabular}{|c|c|c|c|c|c|c|c|}
\hline \multirow{3}{*}{ Pengetahuan } & \multicolumn{4}{|c|}{ Perilaku Seksual } & \multirow{2}{*}{\multicolumn{2}{|c|}{ Jumlah }} & \multirow{3}{*}{$p$ value } \\
\hline & \multicolumn{2}{|c|}{ Berat } & \multicolumn{2}{|c|}{ Ringan } & & & \\
\hline & $\mathbf{N}$ & $\%$ & $\mathbf{n}$ & $\%$ & $\mathbf{n}$ & $\%$ & \\
\hline Tidak baik & 15 & 65,2 & 8 & 34,8 & 23 & $\overline{100,0}$ & \\
\hline Baik & 14 & 33,3 & 28 & 66,7 & 42 & 100,0 & $\mathbf{0 , 0 1 3}$ \\
\hline Total & 29 & & 36 & & 65 & & \\
\hline
\end{tabular}




\section{c. Pengaruh Faktor Sikap dengan Perilaku Seksual Pada Remaja di SMA Karya Handayani Langga Payung Tahun 2020}

Berdasarkan Berdasarkan distribusi sikap pada remaja di SMA Karya Handayani Langga Payung Tahun 2020 sebagian besar dengan sikap positif yaitu 36 orang $(55,4 \%)$ dan sebanyak 29 orang $(44,6 \%)$ dengan sikap negatif. Hasil uji statistik dengan uji Chi Square menunjukkan tidak ada hubungan yang signifikan antara sikap dengan perilaku seksual $(\mathrm{p}=0,301)$.

Sikap adalah respon tertutup seseorang terhadap suatu stimulus atau objek, baik yang bersifat internal maupun eksternal sehingga manifestasinya tidak dapat dilihat secara langsung, tetapi hanya dapat ditafsirkan. Sikap menunjukkan adanya kesesuaian respon terhadap stimulus tertentu (Sunaryo, 2010).

Penelitian ini senada dengan hasil penelitian Ningsih (2016) tentang hubungan pengetahuan dan sikap dengan perilaku berisiko seks bebas anak jalanan di rumah singgah Kota Klaten menunjukkan tidak ada hubungan antara sikap $(\mathrm{p}$ value $=5,53>0,05$ ), dengan perilaku berisiko seks bebas anak jalanan di Rumah Singgah Kota Klaten.

Tabel 3. Tabulasi Silang Hubungan Faktor Sikap dengan Perilaku Seksual Pada Remaja di SMA Karya Handayani Langga Payung Tahun 2020

\begin{tabular}{lccccccc}
\hline \multirow{2}{*}{ Sikap } & \multicolumn{4}{c}{ Perilaku Seksual } & \multirow{2}{*}{ Jumlah } & \multirow{2}{*}{$\boldsymbol{p}$ value } \\
\cline { 2 - 6 } & \multicolumn{3}{c}{ Berat } & \multicolumn{2}{c}{ Ringan } & & \\
\cline { 2 - 6 } & $\mathbf{N}$ & $\mathbf{\%}$ & $\mathbf{n}$ & $\mathbf{\%}$ & $\mathbf{n}$ & $\mathbf{\%}$ & \\
\hline Negatif & 15 & 51,7 & 14 & 48,3 & 29 & 100,0 & \multirow{2}{*}{$\mathbf{0 , 3 0 1}$} \\
Positif & 14 & 38,9 & 22 & 61,1 & 36 & 100,0 & \\
\hline Total & $\mathbf{2 9}$ & & $\mathbf{3 6}$ & & $\mathbf{6 5}$ & & \\
\hline
\end{tabular}

\section{d. Pengaruh Faktor Media Informasi dengan Perilaku Seksual Pada Remaja di SMA Karya Handayani Langga Payung Tahun 2020}

Berdasarkan distribusi media informasi pada remaja di SMA Karya Handayani Langga Payung Tahun 2017 sebagian besar dengan media informasi baik yaitu 33 orang $(50,8 \%)$ dan sebanyak 32 orang $(49,2 \%)$ dengan media informasi tidak baik. Hasil uji statistik dengan uji Chi Square menunjukkan ada hubungan yang signifikan antara media informasi dengan perilaku seksual $(\mathrm{p}=0,018)$.

Menurut Sarwono (2012), ada beberapa faktor yang dianggap berperan dalam munculnya permasalahan seksual pada remaja, diantaranya perubahan hormonal yang dapat meningkatkan hasrat seksual, penyebaran informasi yang salah misalkan dari buku dan VCD porno, rasa ingin tahu yang sangat besar serta kurangnya pengetahuan yang didapat dari orangtua maupun sekolah. Terdapat juga beberapa alasan lain yang menyebabkan remaja melakukan seks pranikah diantaranya sebagai bukti cinta dan sangat mencintai pacar, dijanjikan akan menikah, takut mengecewakan pacar dan takut diputus pacar.

Penelitian Rohmawati (2008), paparan media massa, baik cetak (koran, majalah, buku-buku porno) maupun elektronik (TV, VCD, Internet), mempunyai pengaruh terhadap remaja untuk melakukan hubungan seksual pranikah.

Menurut asumsi peneliti bahwa, meningkatnya minat seksual remaja mendorong bagi remaja itu sendiri untuk selalu berusaha mencari informasi dalam berbagai bentuk, terlepas benar tidaknya informasi tersebut. Sumber informasi dapat diperoleh dengan bebas mulai dari teman sebaya, bukubuku, film, video, bahkan dengan mudahnya membuka situs-situs lewat internet, namun ironisnya sangat sedikit remaja memperoleh pendidikan seksual dari guru ataupun orangtua sehingga tidak jarang remaja melangkah sampai tahap percobaan.

Tabel 4. Tabulasi Silang Hubungan Faktor Media Informasi dengan Perilaku Seksual Pada Remaja di SMA Karya Handayani Langga Payung Tahun 2020

\begin{tabular}{|c|c|c|c|c|c|c|c|}
\hline \multirow{3}{*}{ Media Informasi } & \multicolumn{4}{|c|}{ Perilaku Seksual } & \multirow{2}{*}{\multicolumn{2}{|c|}{ Jumlah }} & \multirow{3}{*}{$p$ value } \\
\hline & \multicolumn{2}{|c|}{ Berat } & \multicolumn{2}{|c|}{ Ringan } & & & \\
\hline & $\mathbf{N}$ & $\%$ & $\mathbf{n}$ & $\%$ & $\mathbf{N}$ & $\%$ & \\
\hline Tidak baik & 19 & 59,4 & 13 & 40,6 & 32 & 100,0 & \\
\hline Baik & 10 & 30,3 & 23 & 69,7 & 33 & 100,0 & 0,018 \\
\hline Total & 29 & & 36 & & 65 & & \\
\hline
\end{tabular}




\section{e. Pengaruh Faktor Peran Orangtua dengan Perilaku Seksual Pada Remaja di SMA Karya Handayani Langga Payung Tahun 2020}

Berdasarkan distribusi peran orangtua pada remaja di SMA Karya Handayani Langga Payung Tahun 2020 sebagian besar dengan peran orangtua baik yaitu 40 orang $(61,5 \%)$ dan sebanyak 25 orang $(38,5 \%)$ dengan peran orangtua tidak baik. Hasil uji statistik dengan uji Chi Square menunjukkan ada hubungan yang signifikan antara peran orangtua dengan perilaku seksual $(\mathrm{p}=0,000)$.

Hal ini sesuai dengan teori perilaku menurut L. Green bahwa perilaku seseorang salah satunya dipengaruh oleh faktor reinforcing, yaitu adanya dukungan atau pengaruh dari orang-orang atau tokoh yang berpengaruh terhadap terjadinya suatu perilaku. Dalam penelitian ini yang berpengaruh salah satunya adalah dari peran orangtua remaja sebaga tokoh yang dihormati dan dianut oleh remaja (Notoatmodjo, 2010).

Hasil penelitian Darmasih, dkk (2011), menjelaskan bahwa peran keluarga berhubungan dengan perilaku seks pranikah remaja. Keadaan keluarga atau situasi keluarga terhadap remaja SMA di Surakarta dalam hal komunikasi dengan orangtua, orangtua yang tidak bercerai, dan remaja tinggal bersama orangtua termasuk dalam kategori baik yaitu sebanyak 77 orang $(67,5 \%)$. Sedangkan yang tidak baik yaitu sebanyak 37 orang $(32,5 \%)$. Orangtua adalah tokoh penting dalam perkembangan identitas remaja. Orangtua dapat membangun hubungan dan merupakan sistem dukungan ketika remaja menjajaki suatu dunia sosial yang lebih luas dan lebih kompleks.

Tabel 5. Tabulasi Silang Hubungan Faktor Peran Orangtua dengan Perilaku Seksual Pada Remaja di SMA Karya Handayani Langga Payung Tahun 2020

\begin{tabular}{lccccccc}
\hline \multirow{2}{*}{ Peran orangtua } & \multicolumn{4}{c}{ Perilaku Seksual } & \multirow{2}{*}{ Jumlah } & \multirow{2}{*}{$\boldsymbol{p}$ value } \\
\cline { 2 - 6 } & \multicolumn{3}{c}{ Berat } & \multicolumn{2}{c}{ Ringan } & & \\
\cline { 2 - 6 } & $\mathbf{N}$ & $\mathbf{\%}$ & $\mathbf{n}$ & $\mathbf{\%}$ & $\mathbf{n}$ & $\mathbf{\%}$ & \\
\hline Tidak baik & 18 & 72,0 & 7 & 28,0 & 25 & 100,0 & \multirow{2}{*}{$\mathbf{0 , 0 0 0}$} \\
Baik & 11 & 27,5 & 29 & 72,5 & 40 & 100,0 & \\
\hline \multicolumn{1}{c}{ Total } & $\mathbf{2 9}$ & & $\mathbf{3 6}$ & & $\mathbf{6 5}$ & & \\
\hline
\end{tabular}

\section{f. Pengaruh Faktor Teman Sebaya dengan Perilaku Seksual Pada Remaja Di SMA Karya Handayani Langga Payung Tahun 2020}

Berdasarkan distribusi teman sebaya pada remaja di SMA Karya Handayani Langga Payung Tahun 2020 sebagian besar dengan teman sebaya tidak baik yaitu 33 orang $(50,8 \%)$ dan sebanyak 32 orang $(49,2 \%)$ dengan teman sebaya baik. Hasil uji statistik dengan uji Chi Square menunjukkan ada hubungan yang signifikan antara teman sebaya dengan perilaku seksual $(\mathrm{p}=0,000)$.

Hal ini selaras dengan teori Green yang menyatakan bahwa salah satu faktor penguat yang mempengaruhi perilaku seksual remaja adalah teman sebaya (Notoatmodjo, 2010). Hal ini sesuai teori yang dikemukakan oleh Dewi (2012), yang berpendapat bahwa teman sebaya merupakan faktor penguat terhadap pembentukan perilaku remaja termasuk perilaku seksual.

Hasil penelitian ini sejalan dengan penelitian yang dilakukan oleh Maryatun (2013), mengenai peran teman sebaya terhadap perilaku seksual pranikah pada remaja di SMA Muhammadiyah 3 Surakarta bahwa sebagian besar remaja (84\%) yang berperilaku seksual pranikah sebanyak (62\%) menyebutkan adanya peran/pengaruh dari teman sebaya.

Tabel 6. Tabulasi Silang Hubungan Faktor Teman Sebaya dengan Perilaku Seksual di SMA Karya Handayani Langga Payung Tahun 2020

\begin{tabular}{|c|c|c|c|c|c|c|c|}
\hline \multirow{3}{*}{ Teman Sebaya } & \multicolumn{4}{|c|}{ Perilaku Seksual } & \multirow{2}{*}{\multicolumn{2}{|c|}{ Jumlah }} & \multirow{3}{*}{$p$ value } \\
\hline & \multicolumn{2}{|c|}{ Berat } & \multicolumn{2}{|c|}{ Ringan } & & & \\
\hline & $\mathbf{N}$ & $\%$ & $\mathrm{n}$ & $\%$ & $\mathbf{n}$ & $\%$ & \\
\hline Tidak baik & 22 & 66,7 & 11 & 33,3 & 33 & 100,0 & \\
\hline Baik & 7 & 21,9 & 25 & 78,1 & 32 & 100,0 & 0,000 \\
\hline Total & 29 & & 36 & & 65 & & \\
\hline
\end{tabular}




\section{g. Pengaruh Faktor Lingkungan Sosial dengan Perilaku Seksual Pada Remaja di SMA Karya Handayani Langga Payung Tahun 2020}

Berdasarkan Berdasarkan distribusi lingkungan sosial siswa pada remaja di SMA Karya Handayani Langga Payung Tahun 2020 sebagian besar lingkungan sosial baik yaitu 37 orang $(56,9 \%)$ dan sebanyak 28 orang $(43,1 \%)$ dengan lingkungan sosial tidak baik. Hasil uji statistik dengan uji Chi Square menunjukkan ada hubungan yang signifikan antara lingkungan sosial dengan perilaku seksual $(\mathrm{p}=0,000)$.

Pada masa remaja, hubungan sosial memiliki peran yang sangat penting bagi remaja. Remaja mulai memperluas pergaulan sosialnya dengan teman-teman sebayanya. Remaja lebih sering berada di luar rumah bersama teman-teman sebayanya, karena itu dapat dimengerti bahwa pengaruh teman-teman sebayanya pada sikap, minat penampilan dan perilaku lebih besar dari pada pengaruh orangtua. Hubungan individu dengan lingkungan sosial saling mempengaruhi.

Lingkungan sangat besar pengaruhnya terhadap perilaku seseorang. Jika seseorang berada ditempat atau lingkungan yang berbeda dengan lingkungan sebelumnya, secara otomatis dia akan mengubah perilakunya demi kelangsungan hidupnya. Dia akan mengubah perilakunya agar bisa diterima dilingkungan baru tersebut. Lingkungan yang beraneka ragam merupakan salah satu faktor yang mempengaruhi terhadap pembentukan dan perkembangan perilaku individu. Baik lingkungan fisik maupun lingkungan sosio-psikologis, termasuk di dalamnya adalah belajar. Hubungan individu dengan lingkungannya ternyata memiliki hubungan timbal balik lingkungan mempengaruhi individu dan individu mempengaruhi lingkungan (Amaliyasari, 2008).

Hasil penelitian tersebut sejalan dengan penelitian yang dilakukan oleh Kalpika (2011), Daerah Prostitusi Dolly berkontribusi $71 \%$ terhadap perilaku seks pranikah remaja kawasan ini. Fakta yang mengejutkan sebagai gambaran langsung dampak wilayah bisnis prostitusi ini terhadap perilaku remaja antara lain 40,7\% remaja kawasan prostitusi Dolly pernah meraba/diraba organ intim pasangannya. Ironisnya, 11,3\% remaja Prostitusi Dolly pernah berhubungan seksual pranikah dengan pacarnya (Kalpika, 2011).

Tabel 7.Tabulasi Silang Hubungan Faktor Lingkungan Sosial dengan Perilaku Seksual di SMA Karya Handayani Langga Payung Tahun 2020

\begin{tabular}{|c|c|c|c|c|c|c|c|}
\hline \multirow{3}{*}{ Lingkungan sosial } & \multicolumn{4}{|c|}{ Perilaku Seksual } & \multirow{2}{*}{\multicolumn{2}{|c|}{ Jumlah }} & \multirow{3}{*}{$p$ value } \\
\hline & \multicolumn{2}{|c|}{ Berat } & \multicolumn{2}{|c|}{ Ringan } & & & \\
\hline & $\mathbf{N}$ & $\%$ & n & $\%$ & $\mathbf{n}$ & $\%$ & \\
\hline Tidak baik & 20 & 71,4 & 8 & 28,6 & 28 & 100,0 & \\
\hline Baik & 9 & 24,3 & 28 & 75,7 & 37 & 100,0 & $\mathbf{0 , 0 0 0}$ \\
\hline Total & 29 & & 36 & & 65 & & \\
\hline
\end{tabular}

\section{Analisis Multivariat}

Analisis multivariat dalam penelitian ini menggunakan uji regresi logistik berganda yaitu salah satu pendekatan model statistik untuk menganalisis pengaruh beberapa variabel independen (lebih dari satu) terhadap variabel dependen kategorik yang bersifat dikotomi atau binary.

Tabel 7. Hasil Akhir Regresi Logistik Berganda

\begin{tabular}{lccccc}
\hline \multirow{2}{*}{ Variabel } & \multirow{2}{*}{ B } & \multirow{2}{*}{ Sig } & \multirow{2}{*}{ Exp B } & \multicolumn{2}{c}{ 95\%CI } \\
\cline { 5 - 6 } & & & & Lower & Upper \\
\hline Peran & .764 & 0.042 & 2.146 & 1.519 & 8.882 \\
Teman & 1.080 & 0.038 & 2.944 & 1.760 & 11.404 \\
Cingkungan & 1.314 & 0.024 & 3.722 & 1.838 & 13.343 \\
\hline
\end{tabular}

Hasil analisis regresi logistik juga menunjukkan bahwa variabel-variabel peran orangtua dengan nilai $\mathrm{p}=0,042$, teman sebaya dengan nilai $\mathrm{p}=0,038$, dan lingkungan sosial dengan nilai $\mathrm{p}=0,024$ berpengaruh terhadap perilaku seksual pada remaja di SMA Karya Handayani Langga Payung tahun 2020. Variabel yang paling dominan berpengaruh terhadap perilaku seksual adalah variabel lingkungan sosial dengan nilai $\mathrm{RP}=3.722$.

Berdasarkan hasil analisis regresi logistik, variabel peran orangtua diperoleh nilai RP sebesar 2.146 artinya siswa yang mendapat peran orangtua tidak baik 2.146 kali lebih besar dengan perilaku seksual berat dibanding dengan perilaku seksual ringan, variabel teman sebaya diperoleh nilai RP sebesar 2.944 artinya siswa yang teman sebaya tidak baik 2.944 kali lebih besar dengan 
perilaku seksual berat dibanding dengan perilaku seksual ringan, dan variabel lingkungan sosial diperoleh nilai RP sebesar 3.722 artinya siswa yang lingkungan sosial tidak baik 3.722 kali lebih besar dengan perilaku seksual berat dibanding dengan perilaku seksual ringan.

\section{KESIMPULAN}

Tidak terdapat pengaruh umur terhadap perilaku seksual pada remaja di SMA Karya Handayani Langga Payung tahun 2020, Terdapat pengaruh pengetahuan terhadap perilaku seksual pada remaja di SMA Karya Handayani Langga Payung tahun 2020, Tidak terdapat pengaruh sikap terhadap perilaku seksual pada remaja di SMA Karya Handayani Langga Payung tahun 2020, Terdapat pengaruh media informasi terhadap perilaku seksual pada remaja di SMA Karya Handayani Langga Payung tahun 2020, Terdapat pengaruh peran orangtua terhadap perilaku seksual pada remaja di SMA Karya Handayani Langga Payung tahun 2020, Terdapat pengaruh teman sebaya terhadap perilaku seksual pada remaja di SMA Karya Handayani Langga Payung tahun 2020, Terdapat pengaruh lingkungan sosial terhadap perilaku seksual pada remaja di SMA Karya Handayani Langga Payung tahun 2020.

\section{REFERENSI}

Amaliyasari Y, Puspitasari N. 2008. Perilaku Seksual Anak Usia Pra Remaja Di Sekitar Lokalisasi dan Faktor Yang Mempengaruhi. The Indonesian Journal of Public Health. Vol 5. N0 1.: 31-38. Juli 2008

Dewi, H.E. (2012). Memahami Perkembangan Fisik Remaja. Yogyakarta: Gosyen Publishing.

Kalpika, 2011. Perilaku Seksual Pranikah Remaja yang Berdomisili di Sekitar Kawasan Lokalisasi Kota Surabaya, adln.fkm.unair.ac.id, diakses pada tanggal 3 Juli 2017

Maryatun, 2013. Peran Teman Sebaya terhadap Perilaku Seksual Pra Nikah pada Remaja di SMA Muhammadiyah 3 Surakarta. GASTER 10(1).

Notoatmodjo. 2010. Pendidikan Kesehatan dan Ilmu Perilaku. Jakarta: Rineka Cipta.

Notoatmodjo. 2012. Promosi Kesehatan dan Perilaku Kesehatan. Jakarta: Rineka Cipta.

Poltekkes Depkes Jakarta I. 2010.Kesehatan Remaja: Problem dan Solusinya. Jakarta: Salemba Medika.

Pratiwi NL dan Hari B. 2010. Analisis hubungan perilaku seks pertama kali tidak aman pada remaja usia 1524 tahun dan kesehatan reproduksi. Buletin Penelitian Sistem Kesehatan.

Rohmahwati D.A., Lutfiati, A., Sri M., 2008. Pengaruh Pergaulan Bebas Dan Vcd Porno Terhadap Perilaku Remaja Di Masyarakat. Diakses Tanggal 19 Mei 2017.

Sarwono, S. 2012. Psikolog Remaja. Jakarta: PT.Raja Grafindo Persada.

Sunaryo. 2010. Psikologi Untuk Remaja. Jakarta: EGC.

World Health Organization, 2009. Sexually Transmitted Infections. Available at:http://www.who.int/topics/sexually_transmitted_infections/en. Maret 2017. 